\title{
Controversy of calcium antagonists: is there a rational differential therapy?
}

\author{
Thomas F. Lüscher, René R. Wenzel, Georg Noll \\ Cardiology, University Hospital/Inselspital, Bern, Switzerland
}

Calcium antagonists are among the most frequently used medications, particularly for the treatment of hypertension and coronary heart disease. Three classes of calcium antagonists can be differentiated, namely (i) dyhydropyridine (e.g. nifedipine, etc.), (ii) verapamil, and (iii) diltiazem. All calcium antagonists are potent vasodilators. First generation dihydropyridine increases the heart rate while verapamil and diltiazem decrease or do not alter the heart rate. The new dihydropyridines do not or only mildly influence heart rate. Although they are efficacious in decreasing blood pressure and have anti-anginal effects, their safety, especially in terms of their effects on the survival of patients with coronary heart disease and those with hypertension, has been questioned in recent publications. A meta-analysis by Curt Furberg found that patients with coronary heart disease treated with short acting nifedipine had a dose dependent increase in mortality compared to the control group. This negative effect has only been found at very high doses of $60 \mathrm{mg}$ and higher. In this meta-analysis, studies were included which investigated the effects of short acting nifedipine and mortality and morbidity were not necessarily used as endpoints in all the strains.

Recently, two case controlled studies on hypertensive patients were published. They showed that patients treated with short acting nifedipine had a higher rate of myocardial infarction than those treated with $\beta$ blockers. These results and the reports in the media have made physicians in clinic and practice, as well as their patients extremely insecure.

Calcium antagonists have an anti-hypertensive and anti-anginal effect and probably also have antiatherosclerosis properties. Prospective, randomized studies regarding the effects on mortality and morbidity such as those carried out in the $70^{\prime}$ 's and 80 's for $\beta$ blockers, diuretics and older antihypertensives, are lacking for calcium antagonists (as well as for ACEinhibitors) in patients with hypertension and stable angina pectoris. The STONE study in China at least indicated that hypertensive patients administered nifedipine had a decrease in the frequency of cerebral stroke. Less can be said regarding coronary heart disease since the prevalence of this disease is so low in this Asian population. Nevertheless, the results of the retrospective case controlled studies in hypertensive patients should certainly be taken seriously, even though they

Correspondence and offprint requests to: Prof. T. F. Lüscher, Inselspital, Department of Cardiology, Lniversity of Bern. CH-3010 Bern. Switzerland. can not be considered as having resolved the issue One must bear in mind that the patients in these case controlled studies were mostly treated with short acting nifedipine, i.e. pharmacological preparations which are hardly used any more in Europe since the introduction of slow release preparations and long acting calcium antagonists. The effects of calcium antagonists on coronary heart disease in patients with hypertension remains still undetermined. This question will be answered in a few years by the ongoing ALLHAT study and INSIGHT study.

The anti-anginal effect of these substances in patients with stable angina pectoris is uncontested. The APSIS study proved that similar survival rates are obtained with verapamil as with the $\beta$-blocker, metoprolol. Similar results were obtained for slow releasing nifedipine and atenolol in the TIBET study.

Short acting preparations, especially those which stimulate the sympathetic system and, therefore, increase the heart rate, should not be used, or only together with a $\beta$-blocker, in patients with coronary heart disease. In patients with vasospastic angina pectoris, calcium antagonists, especially nifedipine, are the first choice.

Studies with first generation calcium antagonists do not show any positive effect on mortality in patients with unstable angina or acute myocardial infarction. Accordingly, their use for this indication should be considered with great reservation and they should only be used for symptomatic treatment and only after previous beta blockade (to diminish sympathetic activation) in specially selected cases.

For secondary prevention after myocardial infarction, verapamil and diltiazem appear to have a moderately favorable effect only in patients without congestive heart failure. It should be noted that the secondary prevention effects of cholesterol lowering drugs and aspirin in this patient group is at least as important. In coronary patients with heart failure, neither verapamil nor amilodipine nor felodipine had a favorable effect on survival, while diltiazem was even associated with an increase in death rate. Therefore, verapamil, amlodipine and felodipine should only be administered when symptoms are present (ischaemia or angina pectoris) and only to patients who are not candidates for a bypass operation or PTCA.

Presently, it appears worthwhile to use the potential of calcium antagonists and to decrease possible risks in patients with cardiovascular diseases by the use of a differential therapy. It should be especially noted 
that not all calcium antagonists are the same and depending on the diagnosis and type of therapeutic indication, i.e. symptomatic or preventive, an individualized differential therapy must be considered (Fig. 1). For hypertension and stable angina pectoris, calcium antagonists are effective and still may be used. However, short acting dihydropyridines should be definitely avoided. Until the results of prospective studies are available, calcium antagonists should be discontinued and replaced by other antihypertensive drugs before major surgery due to the increased risk of hemorrhage. In patients with unstable angina, calcium antagonists should not be used, or only after administration of $\beta$-blockers. They are not appropriate in acute myocardial infarction. For secondary prevention after myocardial infarction, calcium antagonists are not the first choice and should only be used when adequate left ventricular function is present. Aspirin, $\beta$-blockers, ACE inhibitors and cholesterol reducing drugs should be given preference for this indication. In patients with compromised left ventricular function and heart failure, verapamil, amlodipine and felodipine should be administered only to treat symptoms and not for secondary prevention. In this indication, they should only be considered in patients who are already treated with an ACE inhibitor, diuretic and digitalis and in those in which invasive therapy such as PTCA or bypass for the treatment of ischemia is not possible. In hypertrophic cardiomyopathy or supraventricular arrythmias, phenylakylamine calcium antagonists (verapamil) or those of the benzothiazepine group (diltiazem) are appropriate as selected first like drugs (Fig. 1).

\section{References}

1. Lüscher TF, Wenzel RR, Noll G. Kalziumantagonisten in der Kontroverse: Gibt es eine rationale Differentialtherapie? Dtsch Med Wschr 1996; 121: 532-538

2. The effect of diltiazem on mortality and reinfarction after myocardial infarction. The Multicenter Diltiazem Postınfarction Trial Research Group. N Engl J Med 1988; 319: 385-392

3. Braunwald E. Mechanism of action of calcium-channel-blocking agents. $N$ Engl J Med 1982; 307: 1618-1627

4. DAVITII. Effect of verapamil on mortality and major events after acute myocardial infarction (the Danish Verapamil Infarction Trial II-DAVIT II). Am J Cardiol 1990; 66: 779-785

5. Furberg C, Psaty BM, Meyer JV. Nifedipine: Dose-Related Increase in Mortality in Patients with Coronary Heart Disease. Circulation 1995; 92: 1326-1331

6. Held PH, Yusuf S, Furberg CD. Calcium channel blockers in acute myocardial infarction and unstable angina: an overview. Br Med J 1989; 299; 1187-1192

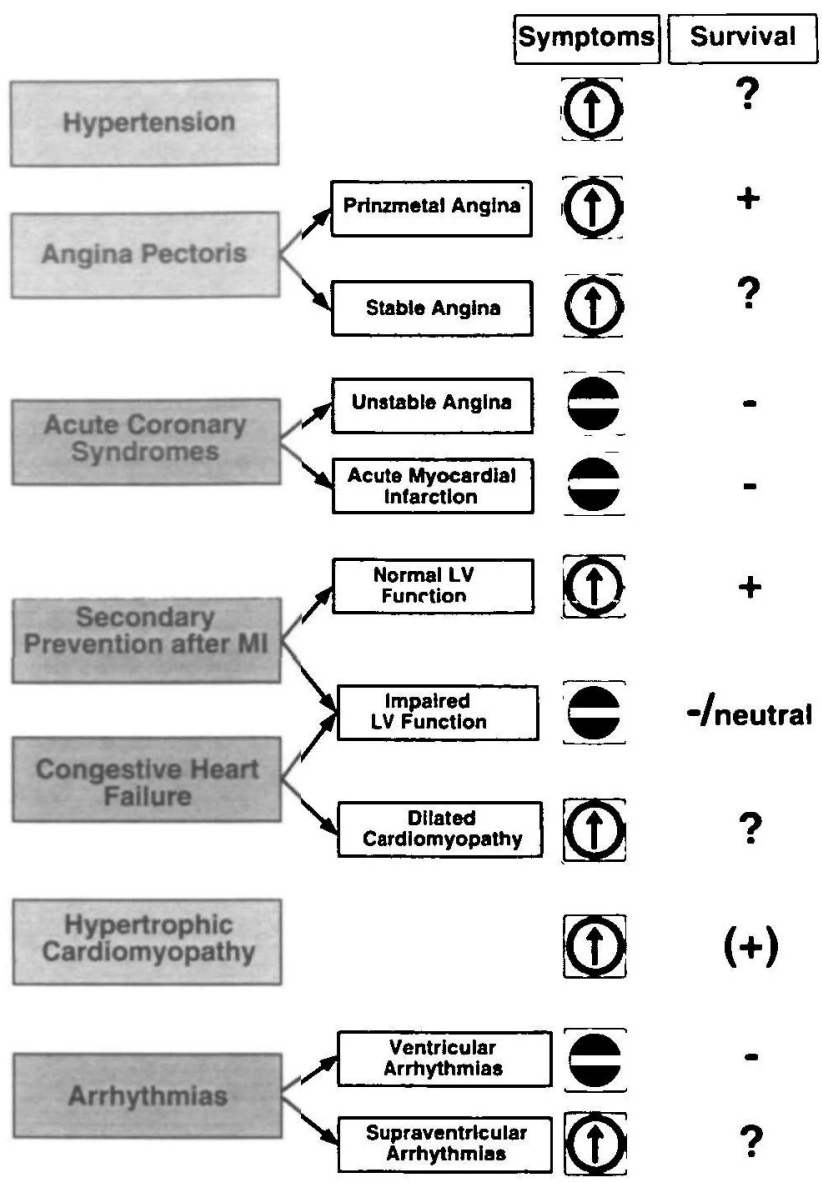

Fig. 1. Differential use of calcium antagonists in patients with cardiovascular disease.

7. Lichtlen PR, Hugenholtz PG, Rafflenbeul W, Hecker H, Jost S, Deckers JW. Retardation of angiographic progression of coronary artery disease by nifedipine. Results of the International Nifedipine Trial on Antiatherosclerotic Therapy (INTACT). INTACT Group Investigators. Lancet 1990; 335: 1109-1113

8. Muller JE, Morrison J, Stone PH et al. Nifedipine therapy for patients with threatened and acute myocardial infarction: a randomized, double-blind, placebo-controlled comparison. Circulation 1984; 69: 740-747

9. Psaty BM, Heckbert SK, Koepsell TD, et al. The risk of myocardial infarction associated with antihypertensive drug therapies. JAMA 1993; 274: 620-625

10. Schroeder JS, Gao SZ, Alderman EL et al. A preliminary study of diltiazem in the prevention of coronary artery disease in heart-transplant recipients [see comments]. N Engl J Med 1993; 328: $164-170$

11. SPRINT. Secondary prevention reinfarction Israeli nifedipine trial (SPRINT). A randomized intervention trial of nifedipine in patients with acute myocardial infarction. The Israeli Sprint Study Group. Eur Heart J 1988; 9: 354-364 